\title{
Sternocephalicus Muscle
}

National Cancer Institute

\section{Source}

National Cancer Institute. Sternocephalicus Muscle. NCI Thesaurus. Code C117980.

A long muscle of the neck that extends from the manubrium sterni to the mandible and branches at the middle of the neck, forming the ventral border of the jugular groove. 